\title{
THE PRACTICALLITY OF RIGID BODY DYNAMICS CONSTRUCTIVIST MODULE AS PHYISC LEARNING RESOURCE OF SENIOR HIGH SCHOOL STUDENTS
}

\author{
Nurdawia $^{* 1)}$, Zulirfan ${ }^{2)}$, Fakhruddin $\mathbf{Z}^{3 \text { ) }}$ \\ ${ }^{1,2,3)}$ Physics Education, University of Riau \\ Email: dewieshamora@gmail.com \\ zirfanaziz69@gmail.com \\ faruqfisika@yahoo.com
}

\begin{abstract}
This study aims to measure the practicality of physics constructivist modules in the dynamics of rotation and rigid body balance using ADDIE's model. The module practicality stages are: preparation, research introduction, practicality testing, filling out questionnaires, analyzing and conclusions, revising, and practical. There are 25 students and one physics teacher who asked using a questionnaire with 5 practical indicators, namely: efficiency, presentation of module material, ease of use, conformity with science, and implementation of constructive elements. The results of module practicality testing data analysis showed that the module efficiency level was 65.83 with the practical category, the module presentation rate was 90.16 with a very practical category, the module's ease of use was 86.08 with a very practical category, the degree of conformity with the science was 95,0 with a very practical category, and the level of implementation of constructive elements is 88.8 with a very practical category. Overall, the practicality of constructivist physics learning modules is 85.17 with a very practical category. Based on the results, it can be concluded that the constructivist physics learning module of rotational dynamics and rigid body balance is declared practical to be used as a source of learning for high school physics students.
\end{abstract}

Keywords: constructivistic module, rigid body dynamics, physics learning

\section{PRAKTIKALITAS MODUL KONSTRUKTIVISTIK DINAMIKA BENDA TEGAR SEBAGAI SUMBER BELAJAR FISIKA SISWA SMA}

\author{
Nurdawia $^{* 1)}$, Zulirfan ${ }^{2)}$, Fakhruddin $Z^{3)}$ \\ ${ }^{1,2,3)}$ Pendidikan Fisika, Universitas Riau
}

\begin{abstract}
Abstrak
Penelitian ini bertujuan untuk mengukur tingkat praktikalitas modul konstruktivisik dinamika rotasi dan keseimbangan benda tegar dalam pembelajaran fisika SMA menggunakan model ADDIE. Adapun tahaptahap pengujian kepraktisan modul yaitu: persiapan, pengenalan penelitian, pengujian kepraktisan, pengisian angket, analisis data dan kesimpulan, revisi modul, dan modul praktis. Terdapat 25 siswa SMA dan satu orang guru fisika SMA senior telah berpartisipasi dalam pengujian kepraktisan ini. Setelah modul diterapkan guru dalam pembelajaran, selanjutnya partisipan diminta memberikan pendapatnya terhadap kemudahan penggunaan modul tersebut melalui instrumen. Instrumen pengumpulan data ini berupa angket dengan 5 indikator praktikalitas yaitu: efesiensi, penyajian materi dalam modul, kemudahan penggunaan, kesesuaian dengan IPA, dan implementasi elemen konstruktivistik. Hasil analisis data pengujian kepraktisan modul menunjukkan bahwa tingkat efesiensi modul adalah 65,83 dengan kategori praktis, tingkat penyajian modul
\end{abstract}


adalah 90,16 dengan kategori sangat praktis, tingkat kemudahan penggunaan modul adalah 86,08 dengan kategori sangat praktis, tingkat kesesuaian dengan IPA adalah 95,0 dengan kategori sangat praktis, dan tingkat implementasi elemen konstruktivistik adalah 88,8 dengan kategori sangat praktis. Secara keseluruhan, tingkat kepraktisan modul pembelajaran fisika konstruktivistik adalah 85,17 dengan kategori sangat praktis. Berdasarkan dapatan tersebut dapat disimpulkan bahwa modul pembelajaran fisika konstruktivistik dinamika rotasi dan kesimbangan benda tegar dinyatakan praktis untuk digunakan sebagai sumber belajar fisika siswa SMA.

Kata kunci: modul konstruktivistik, dinamika benda tegar, pembelajaran fisika

\section{Pendahuluan}

Pendidikan merupakan salah satu aspek penting untuk menjamin kelangsungan hidup bangsa dan negara (Mulyasa, 2014). Pendidikan adalah usaha sadar dan sistematis yang dilakukan oleh orang-orang yang bertanggung jawab untuk mempengaruhi siswa agar mempunyai sifat dan tabiat sesuai dengan citacita pendidikan (Achmad Munib, 2012). Pendidikan bertujuan untuk meningkatkan kualitas siswa, sehingga dalam kegiatan belajar tujuan pembelajaran harus tercapai (Mulyasa, 2014).

Saat ini, kurikulum di Indonesia mengalami masa peralihan dari kurikulum tingkat satuan pendidikan (KTSP) menuju kurikulum 13. Proses pembelajaran pada kurikulum 2013 untuk semua jenjang pendidikan dilaksanankan dengan menggunakan pendekatan saintifik (Permendikbud, 2013).

Kurikulum 2013 menjadikan pendidik sebagai fasilitator yang membantu siswa memecahkan masalah belajar dalam kegiatan pembelajaran. Keberhasilan pencapaian tujuan pendidikan di sekolah banyak bergantung pada bagaimana proses belajar yang dialami siswa sebagai siswa (Slameto, 2003).

Pembelajaran sains dengan menggunakan bahan ajar modul akan sangat bermanfaat bagi guru sains dalam menyampaikan materi kepada siswa (Izaak, 2010).

Fisika merupakan salah satu mata pelajaran yang kurang diminati oleh siswa. Sebagian siswa di sekolah memilih untuk menekuni pengayaan selain mata pelajaran fisika karena menganggap bahwa materi fisika sangat sulit dipahami (Rizky Nilmala, 2016). Reny Viajayani, et al., (2013) melakukan survey terhadap 74 siswa SMA di kota Solo dan menemukan bahwa sebesar $84.6 \%$ siswa setuju bahwa fisika adalah pelajaran yang sulit dipahami.

Ilmu fisika bersifat abstrak serta konsepnya dapat direpresentasikan dalam berbagai bentuk (multirepresentatif), seperti verbal, gambar/diagram, grafik, dan matematis (Waldrip \& Prain, 2007). Rizky (2014) menjelaskan bahwa siswa-siswa pada tingkat sekolah menengah memiliki kemampuan representasi yang rendah sebesar $33 \%$ yang berada pada kategori kurang baik $(<45 \%)$. Padahal kemampuan representasi sangat diperlukan untuk pemahaman konsep-konsep fisika. Kurangnya pemahaman konsep-konsep fisika membuat siswa menganggap bahwa pembelajaran fisika hanya berorientasi pada penggunaan rumus saja (Close \& Heron, 2011).

Indikator lain yang menyebabkan siswa kesulitan memahami konsep fisika adalah kurangnya kontribusi siswa secara aktif dalam menemukan dan memecahkan konsep-konsep yang dipelajari (Rismatul Azizah, et al., 2015). Siswa cenderung hanya menghafal dan mengingat penjelasan guru tentang suatu konsep tanpa pemahaman yang mendalam (Close \& Heron, 2011). Padahal pengetahuan seharusnya tidak diperoleh siswa secara pasif, akan tetapi dibangun sendiri secara aktif sesuai dengan struktur kognitif siswa.

Merujuk teori belajar konstruktivistik, Jean Piaget mengemukakan bahwa pembentukan pengetahuan tersusun atas tiga fase, yaitu 1) eksplorasi, 2) pengenalan konsep, dan 3) aplikasi konsep. Setiap manusia mengalami urutan tersebut untuk mendapatkan pengetahuan secara utuh. Pada proses pembelajaran yang hanya berpusat pada Guru tanpa melibatkan keaktifan siswa, fase eksplorasi tidak muncul sehingga siswa cenderung tidak memahami pengetahuan secara sempurna. 
Peran guru dalam teori belajar Piaget adalah sebagai fasilitator bagi siswa untuk melakukan eksplorasi pengetahuan dengan mengemukakan gagasan sendiri melalui pengalamanpengalaman belajar sebelumnya. Siswa aktif membangun (konstruksi) pengetahuan berlandaskan pada pengalaman belajar sebelumnya, yaitu dengan menghubungkan proses saling mempengaruhi antara pembelajaran terdahulu dengan pembelajaran terbaru (Ruseffendi, 2006).

Suatu cara untuk meningkatkan keaktifan dan kemampuan siswa dalam mengkonstruksi pengetahuan adalah mengembangkan suatu media pembelajaran yang berbasis konstruktivistik. Diantara penelitian yang relevan dilakukan oleh Fitri Dwi Hartati (2018) yang berjudul pengembangan modul FBD (Free Body Diagram) dinamika rotasi dan keseimbangan benda tegar untuk meningkatkan kemampuan siswa SMA dalam menggambar diagram bebas benda. Selanjutnya penelitian yang dilakukan oleh Rismatul Azizah, et al., (2015) mendapatkan bahwa tingkat kemandirian dan keterlibatan siswa dalam proses pembelajaran fisika masih sangat rendah. Sebanyak $88 \%$ siswa mengatakan bahwa pembelajaran fisika dialami adalah dengan metode ceramah. Muhammad Havid (2016) dalam penelitian pendahuluan mengenai tingkat kesulitan materi dinamika dan keseimbangan benda tegar kepada 39 siswa SMA di kota Bandung, menemukan bahwa sebesar $38 \%$ dari siswa menganggap materi dinamika rotasi adalah sulit, dimana kesulitan tersebut sebanyak $50 \%$ berasal dari keterbatasan konsep siswa, dan 45\% kesulitan berasal dari cara guru mengajar. Maharta (2009) mendapatkan bahwa sebagian besar dari siswa yaitu sebanyak $72 \%$ salah menjawab soal mengenai konsep kesetimbangan yang menerapkan hukum I Newton. Hal ini mengidentifikasi bahwa kemampuan menggambar diagram benda bebas (free body diagram) sangat diperlukan untuk meningkatkan hasil belajar pada materi dinamika dan keseimbangan benda tegar. Sa'diah, (2012) menyatakan bahwa pada konsep dinamika rotasi, siswa kurang mampu menganalisis dan menggambarkan diagram bebas gaya-gaya penyebab gerak rotasi sehingga siswa tidak mampu memahami konsep.
Penelitian-penelitian tersebut dinyatakan hasil validasinya dalam empat aspek kelayakan modul menurut BNSP (badan standar nasional pendidikan) yaitu (1) aspek kelayakan isi memiliki nilai $r$ berkisar $0.84-0.95$ dengan kategori sangat baik dan valid (2) aspek kelayakan bahasa memiliki nilai r $0.84-0.96$ dengan kategori valid (3) aspek kelayakan isi dan bahasa memiliki nilai r $0.84-0.96$ dengan kategori valid (4) aspek kegrafikan dan penyajian memiliki nilai $\mathrm{r} 0.84-0.96$ dengan kategori valid.

Selanjutnya, penilaian modul mencakup dua tahap, yaitu tahap validasi oleh para ahli dan tahap uji coba kepada siswa (respon terhadap media). Tahap uji coba adalah kegiatan menggunakan modul pada peserta terbatas, untuk mengetahui keterlaksanaan dan manfaat modul dalam pembelajaran sebelum modul tersebut digunakan secara umum. Data penelitian diperoleh dengan cara penyebaran angket dijadikan sebagai bahan masukan untuk perbaikan modul (Sulistianah, 2008).

Media pembelajaran fisika berupa modul yang telah dibuat dan dikembangkan oleh Fitri Dwi Hartati telah menghasilkan modul yang valid, maka dilakukan penelitian lanjutan ini dengan mengujicobakan kepada siswa untuk mengetahui tingkat kepraktisan dalam penggunaan modul pembelajaran fisika konstruktivistik SMA pada materi dinamika rotasi dan keseimbangan benda tegar.

Hasil penelitian ini diharapkan dapat memberikan manfaat bagi siswa sebagai salah satu inovasi sumber belajar yang dapat menuntun siswa aktif dalam membangun konsep-konsep baru melalui keterkaitannya dengan konsep-konsep dasar yang telah dipelajari sebelumnya sehingga meningkatkan pemahaman konsep fisika. Selanjutnya dapat pula digunakan guru dan sekolah sebagai alternatif bahan ajar yang dapat memudahkan guru dalam melatih pengalaman konstruktivisme siswa dengan pembelajaran berbasis student center learning.

\section{Bahan dan Metode}

Penelitian dilakukan di SMAN Plus Propinsi Riau kelas XI dan waktu penelitian bulan Oktober 2018 - Januari 2019. Jenis penelitian yang digunakan dalam penelitian ini 
adalah penelitian pengembangan (Research \& Development) dengan tahap pengembangan mengikuti model ADDIE menurut Sugiyono (2009). Model ADDIE terdiri dari lima tahap yaitu analysis (analisis), design (perancangan), development (pengembangan), implementation (pelaksanaan), dan evaluation (penilaian). Namun pada penelitian ini, hanya dilakukan penelitian pada tahap implementation, pada tahap analysis-development telah dilakukan oleh peneliti sebelumnya (Fitri Dwi Hartati, 2018). Adapun tahap-tahap implementation untuk uji kepraktisan modul dapat dilihat melalui Gambar 1.

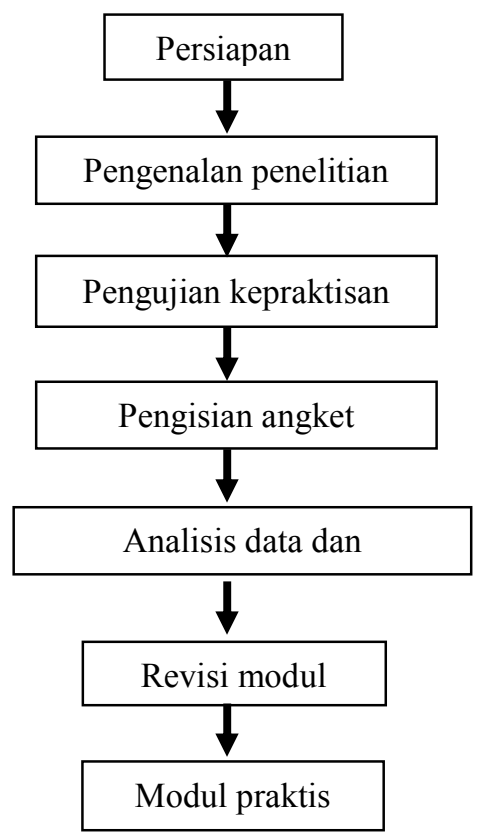

Gambar 1. Tahap-tahap uji kepraktisan, adaptasi dari Hafiz Suhendra (2017).

Tahap persiapan, merupakan langkah awal uji kepraktisan dengan persiapan modul pembelajaran fisika konstruktivistik yang telah divalidasi dan dinyatakan valid oleh pakar pada peneliti sebelumnya, persiapan RPP dan persiapan instrumen. Pengenalan penelitian, Peneliti memberikan pengenalan dan penjelasan mengenai modul pembelajaran fisika konstruktivistik. Hal ini bertujuan agar responden dapat memahami dengan baik dalam menggunakan modul pembelajaran fisika konstruktivistik. Pengujian kepraktisan dilakukan dengan prosedur yaitu menyajikan modul pembelajaran fisika konstruktivistik pada pembelajaran di kelas sesuai dengan kompetensi dasar yang dipelajari yang tercantum dalam RPP. Setelah itu responden melakukan uji kepraktisan dalam penggunaan modul pembelajaran fisika konstruktivistik. Pengisian angket, Setelah pengujian kepraktisan, responden diminta untuk memberikan penilaian terhadap kepraktisan modul pembelajaran fisika konstruktivistik menggunakan lembar pengisian angket. Pernyataanpernyataan pada angket ini melibatkan nilainilai praktis terhadap modul pembelajaran fisika konstruktivistik. Analisis data dan kesimpulan dilaksanakan setelah responden memberi penilaian kepraktisan terhadap penggunaan modul pembelajaran fisika konstruktivistik. Analisis data dan penarikan kesimpulan berdasarkan skor hasil rata-rata tiap aspek penilaian yang diperoleh. Revisi modul dilakukan jika terdapat aspek penilaian pada kategori rendah dan sangat rendah. Revisi dilakukan berdasarkan saran-saran yang diberikan oleh responden setelah pengujian kepraktisan dilaksanakan. Namun demikian, dalam penelitian ini tidak dilakukan tahap ini, karena hanya berfokus pada kepraktisan modul. Modul dinyatakan praktis apabila tiap aspek memperoleh kesimpulan skor hasil ratarata dengan kategori tinggi dan sangat tinggi, maka modul tersebut dapat dinyatakan praktis sehingga bisa layak digunakan dalam skala pemakaian yang luas.

Data yang diperlukan dalam penelitian ini yaitu skor penilaian dari angket oleh responden dan hasil tes formatif. Sedangkan instrumen penelitian yang digunakan adalah angket praktikalitas modul dengan indikator yang diadaptasi dari Badan Standar Nasional Pendidikan (BSNP) dan Riduwan dengan lima (5) indikator yaitu, efesiensi, penyajian materi dalam modul, kemudahan penggunaan, kesesuaian dengan IPA, dan implementasi elemen konstruktivistik (BSNP, 2006; Riduwan, 2005).

Teknik pengumpulan data pada penelitian ini dilakukan dengan pemberian angket kepada 1 orang guru dan 25 orang siswa sebagai responden. Angket yang digunakan berupa pernyataan tertutup yang diberikan secara langsung kepada responden dalam uji coba terbatas setelah proses pembelajaran selesai dilaksanakan.

Analisis data yang digunakan dalam penelitian ini adalah analisis deskriptif. Data 
hasil tanggapan siswa dianalisis dengan langkah sebagai berikut.

a) Memberikan skor untuk setiap item jawaban, Sangat Setuju (4), Setuju (3), Tidak Setuju (2), dan Sangat Tidak Setuju (1).

b) Menjumlahkan skor total tiap validator untuk semua indikator.

c) Pemberian nilai praktikalitas dengan menggunakan persamaan 1 berikut.

$$
P=\frac{\Sigma f}{N} \times 100 \%
$$

$$
\begin{aligned}
\text { Keterangan: } & \\
P & =\text { nilai akhir } \\
f & =\text { perolehan skor } \\
N & =\text { skor maksimum }
\end{aligned}
$$

d) Hasil yang diperoleh diinterpretasikan dengan menggunakan kriteria yang dapat dilihat pada Tabel 1 (Riduwan, 2010).

Tabel 1. Kategori kepraktisan

\begin{tabular}{cl}
\hline Nilai (\%) & \multicolumn{1}{c}{ Kategori } \\
\hline $80<P \leq 100$ & Sangat Praktis \\
$60<P \leq 80$ & Praktis \\
$40<P \leq 60$ & Cukup Praktis \\
$20<P \leq 40$ & Kurang Praktis \\
$P \leq 20$ & Tidak Praktis \\
\hline
\end{tabular}

Modul pembelajaran fisika konstruktivistik pada materi dinamika rotasi dan keseimbangan benda tegar mendapatkan ratarata praktikalitas sebesar 85,17 dengan kategori sangat praktis.

\section{Hasil dan Pembahasan}

Pengujian kepraktisan pada penelitian ini bertujuan untuk mengetahui sejauh mana kelayakan modul pembelajaran fisika konstruktivistik sebagai media pembelajaran agar dapat dipergunakan oleh siswa melalui kemudahan penggunaannya. Menurut Suharsimi Arikunto (2012) makna praktis dalam media pembelajaran adalah media yang memberi kemudahan dalam melaksanakan pembelajaran, memberikan kebebasan kepada siswa untuk berinteraksi dengan media belajar serta dilengkapi petunjuk penggunaan yang jelas.

\section{Penilaian praktikalitas menurut guru}

Hasil penilaian praktikalitas modul pembelajaran fisika konstruktivistik menurut guru dapat dilihat pada Tabel 2.

Tabel 2. Hasil penilaian praktikalitas modul menurut guru

\begin{tabular}{clcc}
\hline No & \multicolumn{1}{|c}{ Indikator } & $\begin{array}{c}\text { P (nilai } \\
\text { akhir) }\end{array}$ & Kategori \\
\hline 1 & $\begin{array}{l}\text { Efisiensi } \\
\text { Penyajian } \\
\text { materi dalam } \\
\text { modul }\end{array}$ & 50,0 & Cukup praktis \\
& 92,0 & Sangat praktis \\
3 & $\begin{array}{l}\text { Kemudahan } \\
\text { penggunaan }\end{array}$ & 87,5 & Sangat praktis \\
4 & $\begin{array}{l}\text { Kesesuaian } \\
\text { dengan IPA }\end{array}$ & 100,0 & Sangat praktis \\
& $\begin{array}{l}\text { Implementasi } \\
\text { elemen } \\
\text { konstruktivistik }\end{array}$ & 90,0 & Sangat praktis \\
\hline & Jumlah & 419,5 & \\
\hline & Rata-rata & 83,9 & Sangat praktis \\
\hline
\end{tabular}

Berdasarkan data pada Tabel 2 dapat dilihat bahwa hasil angket guru terhadap modul pembelajaran fisika konstruktivistik pada materi dinamika rotasi dan keseimbangan benda tegar terdapat indikator yang cukup praktis yaitu pada indikator 1 mengenai efisiensi, dan pada 3 indikator lainnya mendapat kategori sangat praktis yaitu mengenai penyajian materi dalam modul, kemudahan penggunaan, kesesuaian dengan IPA, dan implementasi elemen konstruktivistik. Secara keseluruhan, modul pembelajaran fisika konstruktivistik mendapatkan rata-rata praktikalitas sebesar 83,9 dengan kategori sangat praktis.

\section{Hasil penilaian praktikalitas menurut siswa}

Berdasarkan data pada Tabel 3 dapat dilihat bahwa hasil penilaian praktikalitas melalui angket siswa terhadap modul pembelajaran fisika konstruktivistik pada materi dinamika rotasi dan keseimbangan benda tegar pada semua indikator mendapatkan kategori sangat praktis terhadap aspek efisiensi, penyajian materi dalam modul, kemudahan penggunaan, kesesuaian dengan IPA, implementasi elemen konstruktivistik. 
Secara keseluruhan, modul pembelajaran fisika konstruktivistik mendapatkan rata-rata praktikalitas sebesar 86,45 dengan kategori sangat praktis.

Tabel 3. Hasil penilaian praktikalitas modul menurut siswa

\begin{tabular}{clccc}
\hline No & \multicolumn{1}{|c}{ Indikator } & $\begin{array}{c}\text { Rata } \\
\text {-rata }\end{array}$ & $\begin{array}{c}\text { P (nilai } \\
\text { akhir) }\end{array}$ & $\begin{array}{c}\text { Kate } \\
\text { gori }\end{array}$ \\
\hline 1 & Efisiensi & 3,27 & 81,67 & $\begin{array}{l}\text { Sangat } \\
\text { praktis }\end{array}$ \\
2 & $\begin{array}{l}\text { Penyajian } \\
\text { materi dalam } \\
\text { modul }\end{array}$ & 3,53 & 88,33 & $\begin{array}{l}\text { Sangat } \\
\text { praktis }\end{array}$ \\
3 & $\begin{array}{l}\text { Kemudahan } \\
\text { penggunaan }\end{array}$ & 3,39 & 84,67 & $\begin{array}{l}\text { Sangat } \\
\text { praktis } \\
\text { Sangat } \\
\text { praktis } \\
4\end{array}$ \\
$\begin{array}{l}\text { Kesesuaian } \\
\text { dengan IPA }\end{array}$ & 3,60 & 90,00 & $\begin{array}{l}\text { Sangat } \\
\text { praktis }\end{array}$ \\
\hline $\begin{array}{l}\text { Implementasi } \\
\text { elemen } \\
\text { konstruktivistik }\end{array}$ & 3,50 & 87,60 & \\
\hline & Jumlah & 432,27 & \\
\hline & Rata-rata & 86,45 & $\begin{array}{l}\text { Sangat } \\
\text { praktis }\end{array}$ \\
\hline
\end{tabular}

\section{Hasil tes formatif}

Hasil uji coba kepraktisan modul ini, dalam sebuah pembelajaran yang real maka dilakukan juga 2 kali tes formatif seperti yang ditunjukkan pada Tabel 4.

Tabel 4 Hasil tes formatif siswa

\begin{tabular}{cccc}
\hline \multirow{2}{*}{$\begin{array}{c}\text { Tes } \\
\text { formatif }\end{array}$} & Daya & \multicolumn{2}{c}{ \% siswa } \\
\cline { 3 - 4 } \cline { 3 - 4 } serap & $>\mathrm{KKM}$ & $\leq \mathrm{KKM}$ \\
\hline II & 84,21 & $4 \%$ & $96 \%$ \\
& 90,76 & $4 \%$ & $96 \%$ \\
\hline
\end{tabular}

Berdasarkan Tabel 4. dapat dilihat bahwa 96\% siswa mendapatkan nilai di atas KKM (75) dan hanya 4\% siswa yang mendapatkan nilai di bawah KKM (75). Hal ini menunjukkan bahwa hasil kognitif siswa di atas rata-rata dan dalam kategori baik setelah menggunakan modul pembelajaran fisika konstruktivistik. Hal ini sesuai dengan hasil praktikalitas oleh siswa yang berkategori sangat praktis. Jadi, dengan menggunakan modul pembelajaran fisika konstruktivistik dapat meningkatkan hasil belajar siswa.

\section{Kesimpulan dan Saran}

Berdasarkan hasil penelitian, analisis data, dan pembahasan diperoleh bahwa aspek efisiensi, penyajian materi dalam modul, kemudahan penggunaan, kesesuaian dengan IPA, dan implementasi elemen konstruktivistik secara keseluruhan berkategori sangat praktis. Oleh sebab itu, dapat disimpulkan bahwa modul pembelajaran fisika konstruktivistik pada materi dinamika rotasi dan keseimbangan benda tegar telah praktis berdasarkan aspek efesiensi, penyajian materi dalam modul, kemudahan penggunaan, kesesuaian dengan IPA, dan implementasi elemen konstruktivistik sehingga layak digunakan sebagai sumber belajar yang dapat menuntun siswa dalam membangun konsep-konsep baru melalui pengalaman belajar sebelumnya.

Untuk membantu guru dan siswa dalam proses pembelajaran fisika kelas XI SMA pada materi dinamika rotasi dan keseimbangan benda tegar, penulis menyarankan untuk menggunakan modul pembelajaran fisika konstruktivistik dan dapat dikembangkan oleh peneliti selanjutnya untuk mengetahui keefektifan penggunaannya di lapangan dalam proses pembelajaran fisika.

\section{Daftar Pustaka}

Achmad, Munib, 2012. Pengantar Ilmu Pendidikan. UPT Unnes Press, Semarang.

BSNP, 2006. Standar Isi untuk Satuan Pendidikan Dasar dan Menengah. BSNP, Jakarta.

Close, H. G. \& Heron, R. L., 2011. Student Understanding of Angular Momentum of Classical Particles. Physic Education Research Section, 79 (10), 1068-1078.

Fitri Dwi Hartati, 2018. Pengembangan Modul Pembelajaran Fisika Konstruktivistik pada Materi Dinamika dan Keseimbangan Benda Tegar. Skripsi Program Studi Pendidikan Fisika FKIP Universitas Riau. 
Hafiz Suhendra, 2017. Uji Praktikalitas Alat Peraga Magnet Sebagai Media Pembelajaran IPA Fisika SMP. Skripsi Program Studi Pendidikan Fisika FKIP Universitas Riau.

Izaak H. Weno, 2010. Media Belajar. Jurnal Ilmiah Cakrawala Pendidikan. FKIP Pattimura, Ambon.

Maharta, 2009. Analisis Miskonsepsi Fisika Siswa SMA di Bandar Lampung. Science Education Journal, 1 (1), 36-51.

Mulyasa, 2014. Pengembangan dan Implementasi Kurikulum 2013. Remaja Rosdakarya, Bandung.

Muhammad Havid. 2016. Desain Didaktis Pembelajaran Konsep Torsi dan Momen Inersia Berdasarkan Analisis Kesulitan Belajar Siswa Kelas XI SMA. Repository UPI Education, 134 (7), 459489.

Permendikbud. 2013. Peraturan Menteri Pendidikan dan Kebudayaan Republik Indonesia Nomor 65 Tahun 2013 Tentang Standar Proses Pendidikan Dasar dan Menengah.

Reny Viajayani, Yohanes Radiyono, \& Dwi Teguh Rahardjo, 2013. Pengembangan Media Pembelajaran Fisika Menggunakan Macromedia Flash Pro 8 pada pokok bahasan Suhu dan Kalor. Jurnal Pendidikan Fisika UNS, 1 (1), 150-165.

Riduwan, 2005. Belajar Mudah Penelitian untuk Guru, Karyawan dan Peneliti Pemula. Alfabeta, Bandung.

Rismatul Azizah, Lia Yuliati, \& Eny Latifah, 2015. The Physic Problem Solving Difficulties on High School Student. Jurnal Penelitian Fisika dan Aplikasinya (JPFA), 5 (2), 44-45.
Rizky, 2014. Kemampuan Multirepresentasi Siswa SMA dalam Menyelesaikan Soalsoal Hukum Newton. Jurnal Pendidikan dan Pembelajaran, 8 (3), 134-145. Program Studi Pendidikan Fisika. Universitas Tanjungpura.

Rizky Nirmala, 2016. Penerapan Model Pembelajaran Kooperatif Tipe STAD (Student Team Achievement Division) Disertai Tugas Open Ended untuk Meningkatkan.

Ruseffendi, 2006. Teori Konstruktivisme dalam Sistem Pembelajaran. Nusa Media, Bandung.

Sa'diah, 2012. Remediasi Kesulitan Belajar Siswa Kelas XII IPA MAN 1 Pontianak pada Materi Dinamika Rotasi Menggunakan Model Learning Cycle 5E. Journal Untan, 2177 (2118), 4589-4598.

Slameto, 2003. Belajar dan Faktor-faktor yang Mempengaruhinya. Rineka Cipta. Jakarta.

Sugiyono, 2009. Metode Penelitian dan Pengembangan. Alfabeta, Yogyakarta.

Sulistianah, Dewang, 2008. Program bimbingan bagi siswa Underachiever. Skripsi jurusan psikologi pendidikan dan bimbingan. Bandung. Universitas Pendidikan Indonesia: Tidak diterbitkan.

Suharmisi Arikunto, 2012. Dasar-dasar Evaluasi Pendidikan. Bumi Aksara. Jakarta.

Waldrip, B. \& Prain, V., 2007. An Exploratory Study of Teachers and Students Use of Multi-modal Representation of Concepts in Primary Science. International Journal of Science Education, 28 (15), 1843-1896. 